\title{
Development and implementation of two-stage boost converter for single-phase inverter without transformer for PV systems
}

\author{
Basem E. Elnaghi ${ }^{1}$, Mohamed E. Dessouki ${ }^{2}$, M.N.Abd-Alwahab ${ }^{3}$, Elwy E. Elkholy ${ }^{4}$ \\ ${ }^{1,3}$ Department of Electrical Power and Machines, Suez Canal University, Egypt \\ ${ }^{2}$ Department Electrical Engineering, King Abdulaziz University, Saudi Arabia \\ ${ }^{2}$ Electrical Engineering Department, Port Said University, Egypt \\ ${ }^{4}$ Electrical Engineering Department, Menoufia University, Egypt
}

\section{Article Info \\ Article history: \\ Received Dec 31, 2018 \\ Revised Jul 8, 2019 \\ Accepted Jul 17, 2019 \\ Keywords: \\ DC-DC converters \\ Microcontroller \\ Photovoltaic systems \\ Pulse width modulation inverter \\ Total harmonic distortion

\begin{abstract}
This paper offers a two-stage boost converter for a single-phase inverter without transformer for PV systems. Each stage of the converter is separately controlled by a pulse width modulated signal. A Simulink model of the converter using efficient voltage control topology is developed. The proposed circuit performance characteristics are explained and the obtained simulation results are confirmed through the applied experiments. Moreover, this paper has examined the control circuit of a single-phase inverter that delivers a pure sine wave with an output voltage that has the identical value and frequency as a grid voltage. A microcontroller supported an innovative technology is utilized to come up with a sine wave with fewer harmonics, much less price and an easier outline. A sinusoidal pulse width modulation (SPWM) technique is used by a microcontroller. The developed inverter integrated with the twostage boost converter has improved the output waveform quality and controlled the dead time as it decreased to $63 \mu \mathrm{s}$ compared to $180 \mu \mathrm{s}$ in conventional methods. The system design is reproduced in Proteus and PSIM Software to analyze its operation principle that is confirmed practically.
\end{abstract}

Copyright $\odot 2020$ Institute of Advanced Engineering and Science. All rights reserved.

\section{Corresponding Author:}

Mohamed. E. Dessouki,

Department of Electrical Engineering,

King Abdulaziz University,

Rabigh 21911, Saudi Arabia.

Email: dessouky_m@yahoo.com

\section{INTRODUCTION}

The quality of load matching of Photovoltaic (PV) and AC load types has considered one of the urging problems. The key solution of such a problem has been characterized by the inverter configuration and its capability of supplying pure sine wave and controlled voltage limit for AC loads. The line frequency transformers (LFT) employed in the grid side of transformer-type PV inverters are large and heavyweight, therefore, such inverter systems are bulky and tough to install, while high-frequency transformers (HFT) utilized on the dc-dc stage are much smaller than the line frequency transformer. Nevertheless, they have many power stages that raise the system complexity and decrease both the overall efficiency and system reliability [1-5]. Now, the focus has become to get the extreme energy from the PV system and step up PV output voltage from $24 \mathrm{~V}$ to $100 \mathrm{~V}$ then to $312 \mathrm{~V}$, because of the high cost of the photovoltaic modules. Hence, the 312 VDC is inverted to AC $220 \mathrm{~V}$ (RMS value) successfully by means of single-phase inverter. The requirement of the power rating inverter is increased to run the electrical and digital home equipment efficiently. The majority of the available commercially uninterruptible power. Supplies (UPSs) are quasi-sine wave inverters or square wave inverters. If an electronic device operated by these inverters, it will be damaged because of the contents of the harmonics $[6,7]$. The generation of a pure wave is significance in 
electronics energy but, the majority of the existing sinusoidal wave inverters are costly and the production is straight. The switching technique of SPWM is described as a powerful technique so it was used in a pure sine wave inverter. The PV output DC voltage is raised by a DC-DC converter to a suitable level then it is converted to an AC voltage by the applying SPWM strategy to the inverter using a PIC microcontroller [8, 9]. The SPWM is used in the applications of electronics energy such as UPS, renewable energy system, and motor driver [10]. SPWM techniques are described by fixed amplitude pulses with various duty cycles for each period. The generation of this signal is carried out traditionally by comparing a triangular wave (carrier signal) with a sinusoidal wave (reference signal) that has the required frequency [11-13]. Because of the module of the PWM structure, Microcontroller is able to keep orders to produce the required waveform of the implication of pulse width. The objective of this process is using a peripheral interface controller (PIC) microcontroller instead of the conventional method. Through the system of PIC16f877A, variable frequency pulse width implication signal is supplied by Microcontroller which dominates the gate drive voltage. Microcontroller accomplished control circuit if it is used for grid connection or stand-alone, but this inverter implementation is from a direct supply of photovoltaic cells has completed control circuit in dead time. A Microcontroller is enough easy and adaptable to change the control algorithms with low cost in a real-time and without additional changes in hardware and it decreases the complication of the control circuit of the single-phase inverter bridge [14]. The paper aims to

a. Introduce hardware design for a two-stage boost converter in which each stage is controlled separately by PWM signal for controlling voltage to boost the PV low voltage $\left(15-45 \mathrm{~V}_{\mathrm{DC}}\right)$ to a high DC link voltage $\left(312 \mathrm{~V}_{\mathrm{DC}}\right)$ required for single-phase inverter to produce $220 \mathrm{VAC}$ for integrating with the utility grid without using niegher LFT nor HFT to avoid their drawbacks mentioned above.

b. Develop a simple control circuit for single-phase inverter interfaced by simple flexible controller PIC microcontroller to produce a pure sinusoidal AC voltage according to the grid voltage and frequency $\left(220 \mathrm{~V}_{\mathrm{AC}}, 50 \mathrm{~Hz}\right)$.

\section{THE PROBLEM}

An output voltage of photovoltaic arrays is very low while ac applications need high voltage level, so a single stage boost converter cannot accomplish such a high transformation ratio that implies large input current that would increase the conduction losses in the switching MOSFET. Therefore, the converter efficiency is reduced. Additionally, there is a dangerous reverse recovery problem in the diode [15, 16]. The duty ratio (D) of the converter. Has an inverse relation with the adequacy ( $\Pi$ ) of the converter circuit [17] as given in (1):

$$
\eta=\frac{1}{1+\frac{R_{L}}{(1-D)^{2} R_{\text {load }}}}
$$

$\mathrm{R}_{\mathrm{L}}$ is the self-resistance of the inductor. Therefore, in the consideration for the equation, the duty ratio cannot be increased above a certain maximum limit $(\mathrm{D}>0.9)$ as the feedback loop is difficult to stabilize, moreover, the changes in the transistor state require a finite amount of time. Thus, the two-stage boost converter in cascaded was suggested with a high step-up voltage ratio and maximum efficiency. The main power switch of each stage is supplied with a PWM signal at the same time with little different duty ratio depending on the level of the voltage step-up at each stage. The inverter is used to convert its input DC voltage (converter output) to an AC output voltage. Although the ideal inverter has output voltage waveform that is sinusoidal, the practical inverter has a waveform which is non-sinusoidal and includes harmonics, therefore, the electronic devices driven by this inverter will be damaged as a result of these harmonic contents $[18,19]$. The inverter output harmonics content depends on the number of pulses per cycle in inverter output [19-23]. Some pulses are affected by the circuit and some of the pulses are affected by circuit power losses problem during.

Switching, as well. The high technique of switching will give a share of the high energy losses. These factors should be considered to meet the following requirements: equipment cost, filter size, and power loss in the switching element. The main problem is the dead time control. It is necessary that the dead time period is appropriate to prevent switch damage and harmonic problem. When the dead time is short enough, it will be the reason for damaging to the switches and when it is long, it will be the reason for an increase in the whole harmonic distortion percentage $[10,11]$. The key goals of the paper:

a. It presents a solution of a high quality of load matching between PV and AC loads through enhancing performance of the hardware design elements and supporting them by software package. 
b. The paper has implemented a hardware design for a two-stage boost converter, each stage is controlled separately by PWM signal for controlling the voltage.

c. The paper has also developed another hardware design for a model of inverter interfaced by simple flexible controller PIC microcontroller capable of generating PWM to improve the output voltage waveform.

d. Software package simulation has been developed in Proteus and PSIM to support and validate the proposed hard ware design tools.

\section{PROPOSED TWO-STAGE BOOST CONVERTER CONFIGURATION}

Figure 1 illustrates the main circuit of the proposed converter. It is supposed that the switches are ideal. The input voltage is immediate and fixed and the load is purely resistive. Each stage of the converter is supposed to be operated in continuous conduction mode.

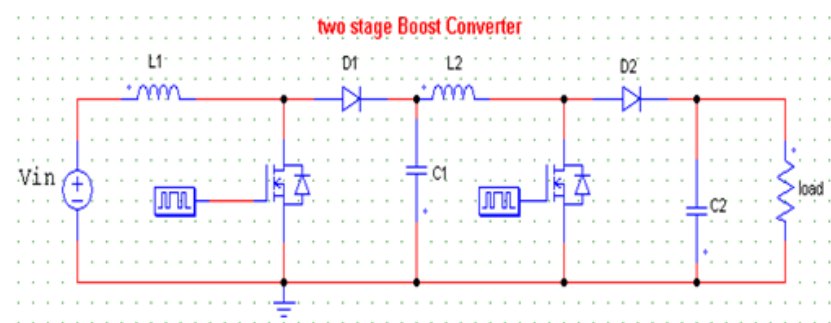

Figure 1. The proposed two-stage boost converter basic circuit design

The voltage conversion ratio for the proposed boost converter will be given by (2) as there are two stages of the boost converter in cascaded

$$
M(D)=\left(\frac{1}{1-D_{1}}\right)\left(\frac{1}{1-D_{2}}\right)
$$

Where $D_{1}$ and $D_{2}$ are the duty ratio for stage 1 and stage 2 respectively. When we concentrate on the input voltage range and output voltage for a special application the duty ratio of both stages can be derived.

\section{THE PROPOSED TWO-STAGE BOOST CONVERTER DIMENSIONING}

The converter input voltage from PV panel is 24 volts and the desired output voltage ranges from 312 to 320 volts, so the duty cycle D varies between 0.923 to 0.925 and one- stage only will not be capable to boost the input voltage to the desired output level as discussed above.

\subsection{Inductor design}

Inductor current $\left(\mathrm{I}_{\mathrm{L}}\right)$ for each stage can be calculated from the input power and output power balance. Input power $=$ output power

$$
\begin{aligned}
& V_{\text {in }} I_{\text {in }}=\frac{V_{o}^{2}}{R} \\
& V_{\text {in }} I_{\text {in }}=\frac{\left(\frac{V_{\text {in }}}{1-D}\right)^{2}}{R}=\frac{V_{\text {in }}^{2}}{(1-D)^{2} R} \\
& I_{L}=\frac{V_{\text {in }}}{(1-D)^{2} R}
\end{aligned}
$$


The maximum inductor current $\left(\mathrm{I}_{\mathrm{Lmax}}\right)$ and minimum inductor current $\left(\mathrm{I}_{\mathrm{Lmin}}\right)$ values as follows

$$
\begin{aligned}
& I_{L \max }=I_{L}+\frac{\Delta i_{l}}{2}=\frac{V_{\text {in }}}{(1-D)^{2} R}+\frac{V_{\text {in }} D T}{2 L} \\
& I_{L \text { min }}=I_{L}-\frac{\Delta i_{l}}{2}=\frac{V_{\text {in }}}{(1-D)^{2} R}-\frac{V_{\text {in }} D T}{2 L}
\end{aligned}
$$

where $V_{i n}, V_{o}, R$ are the input voltage, output voltage and load resistance respectively.

Minimum inductor current $\mathrm{I}_{\mathrm{Lmin}}>0$ for continuous operation, hence

$$
\begin{aligned}
& \frac{V_{\text {in }}}{(1-D)^{2} R}-\frac{V_{\text {in }} D T}{2 L} \geq 0 \\
& L_{\text {min }}=\frac{D(1-D)^{2} R T}{2}=\frac{D(1-D)^{2} R}{2 f}
\end{aligned}
$$

where, $f$ is the switching frequency.

\subsection{Output filter design}

At the output it is desired to limit the peak to peak ripple of the output voltage, so a capacitor filter is required. The output capacitance depends on the duty ratio, switching frequency, and load resistance. For continuous current mode, the minimum value of the filter capacitance $\left(C_{\min }\right)$ is given by $(10)$.

$$
C_{\min }=\frac{V_{o} D T}{R \Delta V_{o}}=\frac{V_{o} D}{R \Delta V_{o} f}
$$

$\Delta \mathrm{V}_{\mathrm{o}}$ is the change in the output voltage. Based on the above equations, the simulation parameters for the proposed two-stage boost converter are illustrated in Table 1 and Table 2:

Table 1. First stage parameters

\begin{tabular}{ll}
\hline Parameters & Value \\
\hline Input voltage, $\mathrm{V}_{\text {in }}$ & $24 \mathrm{~V}$ \\
The output voltage, $\mathrm{V}_{\mathrm{o}}$ & $100 \mathrm{~V}$ \\
The output power, $\mathrm{P}_{\mathrm{o}}$ & $250 \mathrm{~W}$ \\
Duty ratio, $\mathrm{D}_{1}$ & 0.76 \\
Switching frequency, $\mathrm{f}$ & $20 \mathrm{KHz}$ \\
Resistance, $\mathrm{R}$ & $40 \Omega$ \\
Minimum inductance, $\mathrm{L}_{\min }$ & $43.776 \mu \mathrm{H}$ \\
Filter capacitance, $\mathrm{C}_{\min }$ & $19 \mu \mathrm{F}$ \\
Inductor current, $\mathrm{I}_{\mathrm{L}}$ & $10.42 \mathrm{~A}$ \\
\hline
\end{tabular}

Table 2. Second stage parameters

\begin{tabular}{ll}
\hline Parameters & Value \\
\hline Input voltage, $\mathrm{V}_{\text {in }}$ & $100 \mathrm{~V}$ \\
The output voltage, $\mathrm{V}_{\mathrm{o}}$ & $320 \mathrm{~V}$ \\
The output power, $\mathrm{P}_{\mathrm{o}}$ & $250 \mathrm{~W}$ \\
Duty ratio, $\mathrm{D}_{2}$ & 0.68 \\
Switching frequency, $\mathrm{f}$ & $20 \mathrm{KHz}$ \\
Resistance, $\mathrm{R}$ & $390 \Omega$ \\
Minimum inductance, $\mathrm{L}_{\text {min }}$ & $678 \mu \mathrm{H}$ \\
Filter capacitance, $\mathrm{C}_{\mathrm{omin}}$ & $1.74 \mu \mathrm{F}$ \\
Inductor current, $\mathrm{I}_{\mathrm{L}}$ & $2.504 \mathrm{~A}$ \\
\hline
\end{tabular}

\section{SIMULATION RESULTS}

Using the previous calculations for the converter parameters tabulated in Table 1 and Table 2, the proposed boost converter is examined through simulation using PSIM platform as shown in Figure 2. We can observe the output voltage waveform of each stage of the converter, the output voltage for stage 1 and stage 2 are displayed in Figure 3 and Figure 4 respectively. For the control circuit of the two-stage boost converter, a simple PI controller has been employed. Each stage was planned by its isolated PI controller. Each stage output voltage is measured and compared with the reference voltage and the error is entered to the PI controller to amplify the error signal which compared with a triangular signal to generate the pulse width modulated signal. The output voltage waveform is illustrated in Figure 5. 


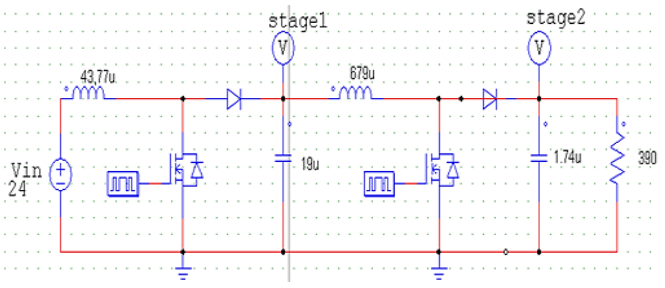

Figure 2. PSIM simulation of the proposed converter

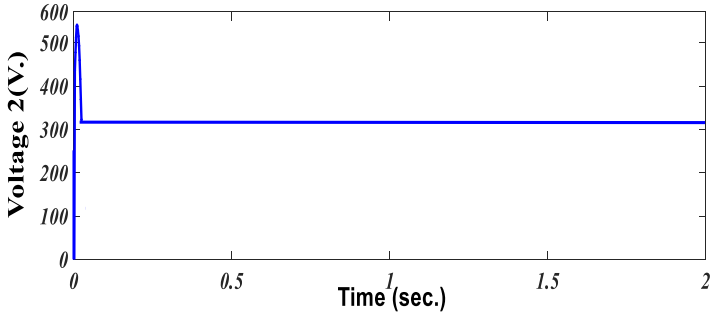

Figure 4. Stage (2) output voltage

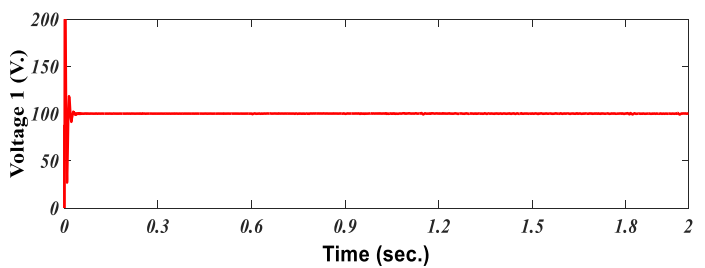

Figure 3. Stage (1) output voltage

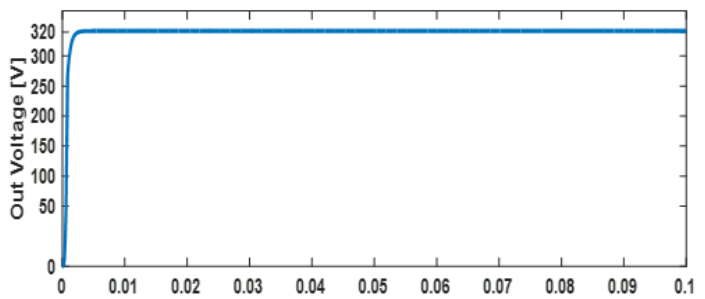

Figure 5. The output voltage of the controlled twostage boost converter

\section{THE PROPOSED OVERALL SYSTEM DESCRIPTION AND PRACTICAL REALIZATION}

The block diagram of the suggested overall system is illustrated in Figure 6. The utilization of full $\mathrm{H}$-bridge inverter circuit is to convert the output DC voltage of the proposed converter to a sinusoidal AC voltage at a required level output voltage and frequency. Producing a sin wave aligned around zero voltage needs both positive and negative voltage across the load. This can be done from a single source by the use of the $\mathrm{H}$ bridge inverter circuit as shown in Figure 7. Switches Q1, Q3, Q2, and Q4 are arranged in sequence in this configuration in standard H-bridge circuit. Both gating signals GQ1 and GQ4 are switched together at positive half cycle while gating signals GQ2 and GQ3 are switched together at the other half cycle [24-28]. The switching signals GQ1 and GQ4 lead the switching signals GQ2 and GQ3 by 180 degrees (half cycle) of the switching control signal. The circuit output has a frequent waveform and it is not sinusoidal [25].

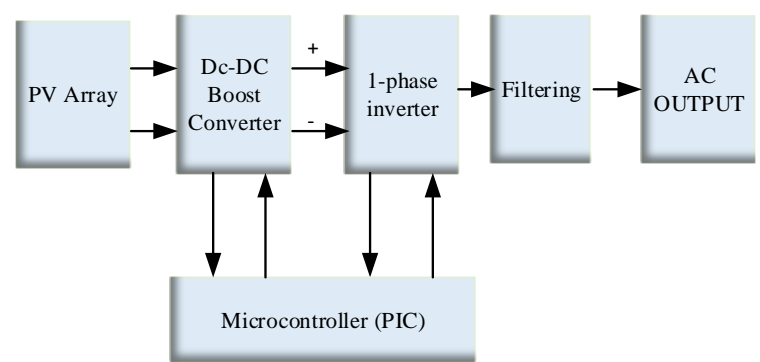

Figure 6. Block diagram of the proposed overall system

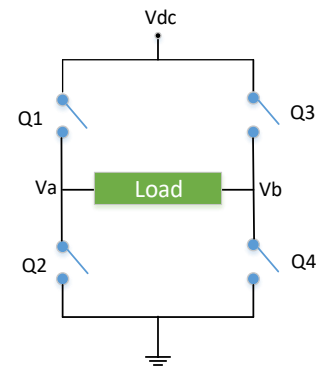

Figure 7. H-bridge single-phase Inverter

The aim of utilization PIC microcontroller is generating the desired signals of SPWM to control the H-bridge MOSFETs. A PIC microcontroller is the core of this system which is evolved to produce an SPWM with the control of dead time. The control of dead time is helpful for decreasing the cost of the capacitor filter. The dead time control is a highly important problem. There were probability interfering signals between ON period switches pair (Q1, Q4) and OFF period switches pair $(\mathrm{Q} 2, \mathrm{Q} 3)$ in the inverter of full-bridge and the reason for the short-term circuit of DC bus [10]. It is necessary for the duration of dead time to be convenient for preventing switch damage and the harmonic content problem also. Dead time is dominated by using the PIC microcontroller. 


\subsection{Software algorithms}

\subsubsection{Generation of gating signals for the proposed converter} Figure 8.

The flowchart for the algorithm used for controlling the proposed two converter is shown in

\subsubsection{Generation of gating signals for single-phase inverter}

The purpose of utilizing PIC microcontroller is to generate SPWM from MCU but in fact, the MCU does not generate SPWM directly. It generates normal PWM. Therefore, the frequency and duty cycle of the PWM signal are adjusted to obtain SPWM, and this is our goal. The flowchart of generating SPWM signals for single phase full bridge inverter program is shown in Figure 9.

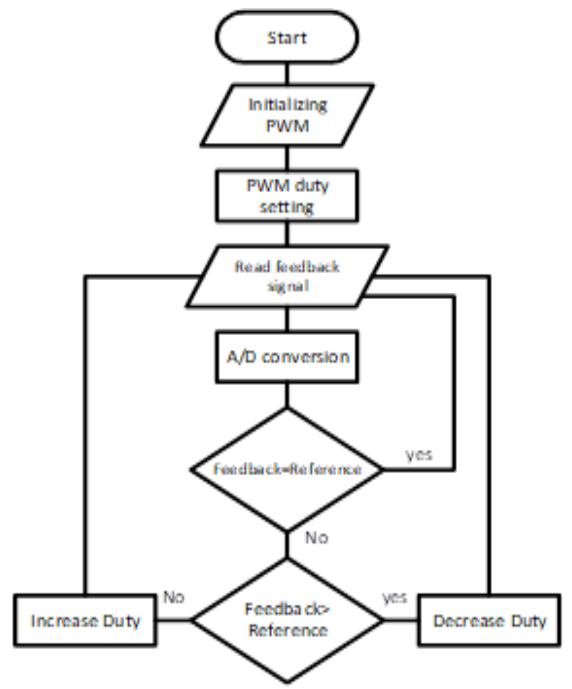

Figure 8. Control algorithm flowchart for the boost converter
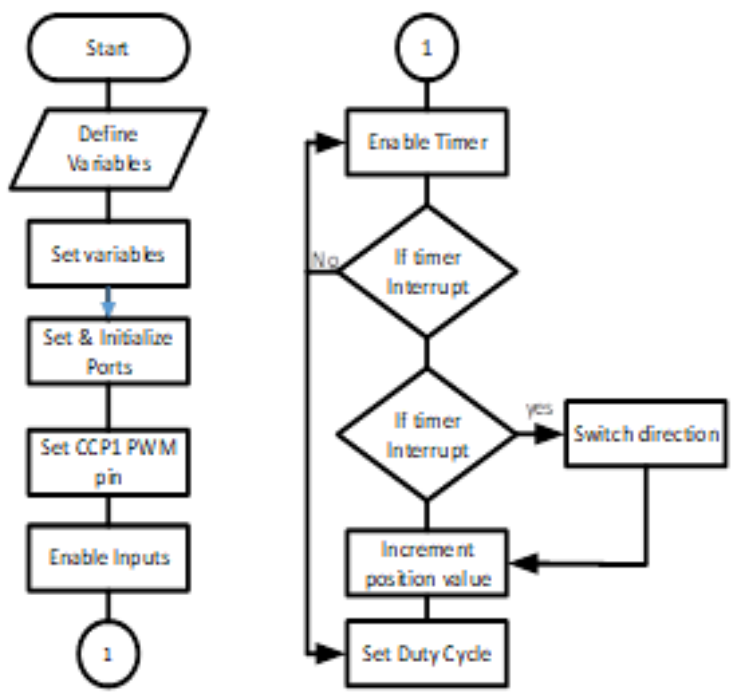

Figure 9. The flowchart for generating SPWM signal for the $1-\phi$ inverter

\subsection{Isolation circuit}

For both isolations the ground of the control circuit from the ground of the power circuit and reducing the effect of control circuit impedance on the converter and inverter performance an isolation circuit is used. Gate drive TLP250 was incorporated.

\section{THE RESULTS AND DISCUSSION}

Figure 10 illustrates the suggested hardware setup of the inverter circuit to get a sine wave AC output voltage with a frequency of $50 \mathrm{~Hz}$ and amplitude of $220 \mathrm{~V} \mathrm{Ac}$. Figure 11, Figure 12, and Figure 13 illustrate the simulation and experimental results of the four PWM control signals resulted for the full bridge single phase inverter.

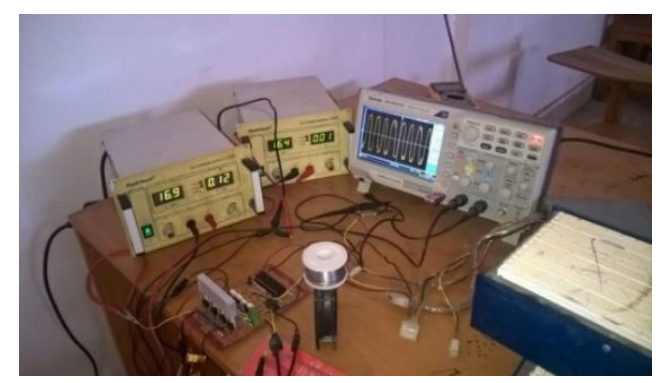

Figure 10. The experimental set up for the $\mathrm{H}$ bridge inverter

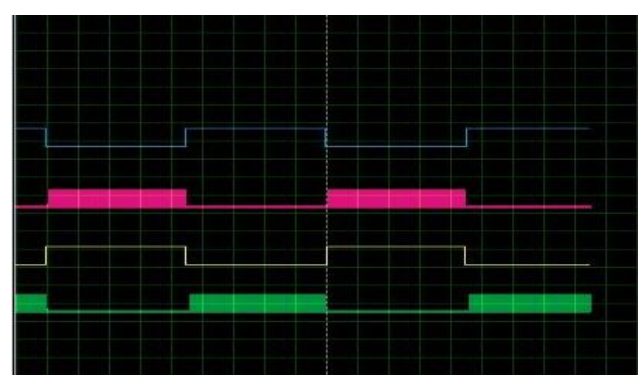

Figure 11. Simulation of PWM signals for the inverter MOSFETs 


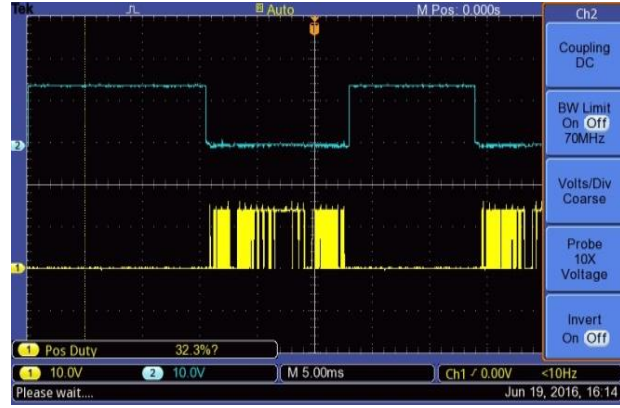

Figure 12. Experimental results of PWM_1 \& SPWM 2 signals

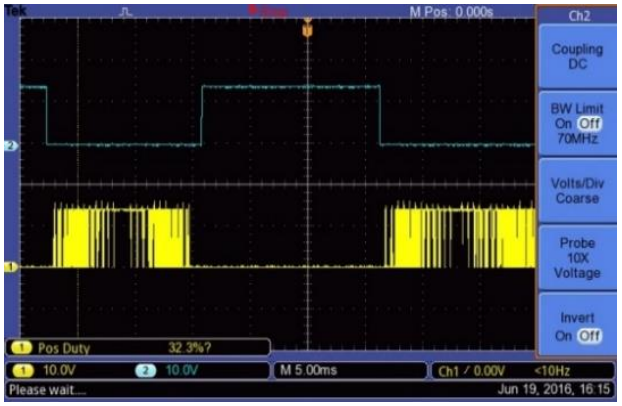

Figure 13. Experimental results of PWM_3 \& SPWM_4 signals

Simulation and experimental results of the output voltage for full bridge single-phase inverter without using the filter are illustrated in Figure 14 and Figure 15 respectively. it can be noticed that the output voltage in real-time implementation of the inverter and its simulation is the same while the output voltage is not a pure sine wave. That to obtain the required output AC signal of sinusoidal wave an LC filter is linked. The output wave frequency obtained from the simulation and experiments is $50 \mathrm{~Hz}$. and it is the same as the grid frequency. It is important to study the total harmonic distortion (THD) of the generated output voltage of the inverter before and after using the filter and they are displayed in Figure 16 and Figure 17 respectively. From Figure 16, the THD of the inverter's output voltage without a filter is $67.3 \%$ (very high), that should be less than 3\% as per IEEE 519-1992 standards for grid-connected inverters.

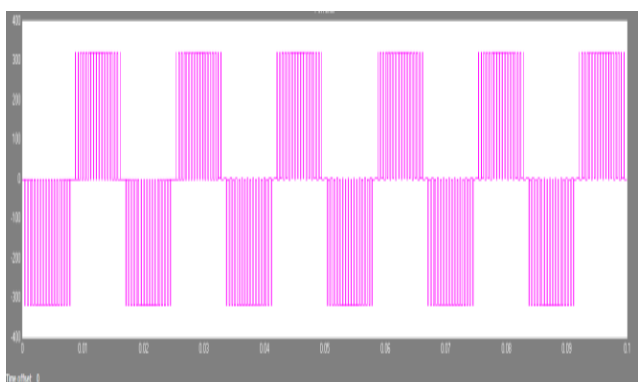

Figure 14. The simulated output voltage of H-bridge single-phase inverter without the filter
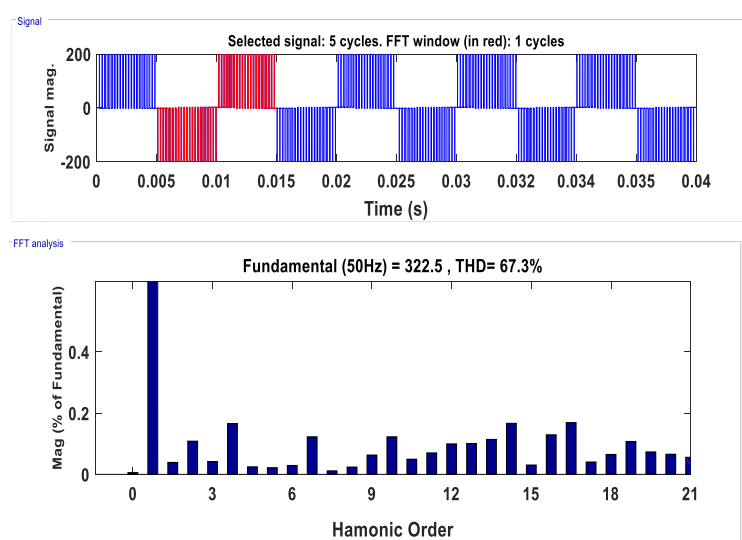

Figure 16. THD of the inverter output voltage without filter

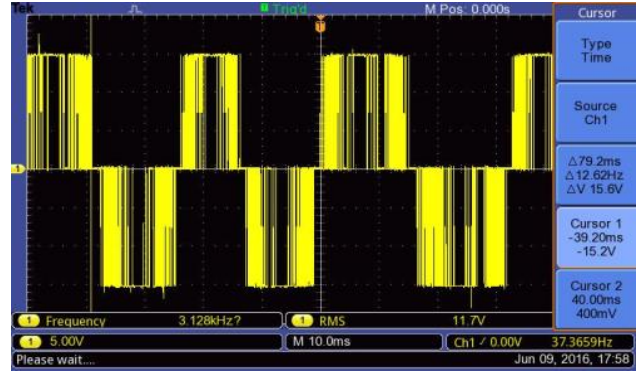

Figure 15. The Experimental output voltage of H-bridge single-phase inverter without the filter
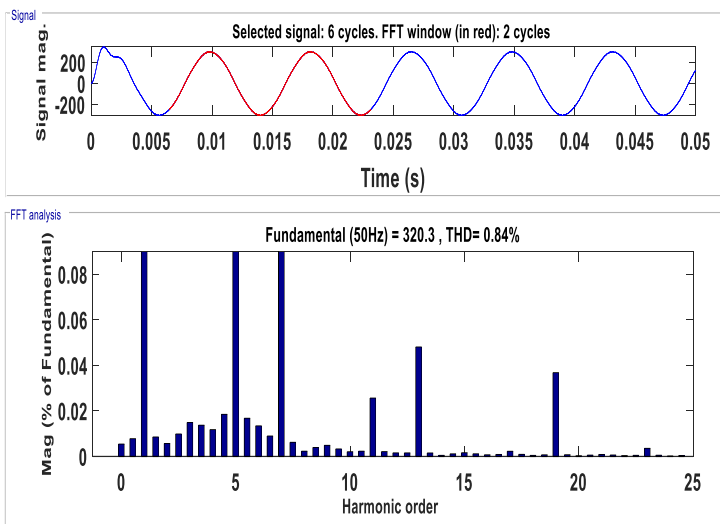

Figure 17. THD of the inverter output voltage with filter 
The corresponding inverter's output voltage THD using the filter is shown in Figure 17, which is $0.84 \%$. This is an acceptable THD value of voltage for grid-connected inverters according to IEEE 519-1992 standards. The inverter design implemented in hardware is tested laboratory and the filtered output voltage is illustrated in Figure 18 and it is observed to be same as the simulations. Figure19 illustrates the measurement of the dead time of the H-bridge inverter waveform and it is from the emulation, it is reduced to $63 \mathrm{Msec}$.

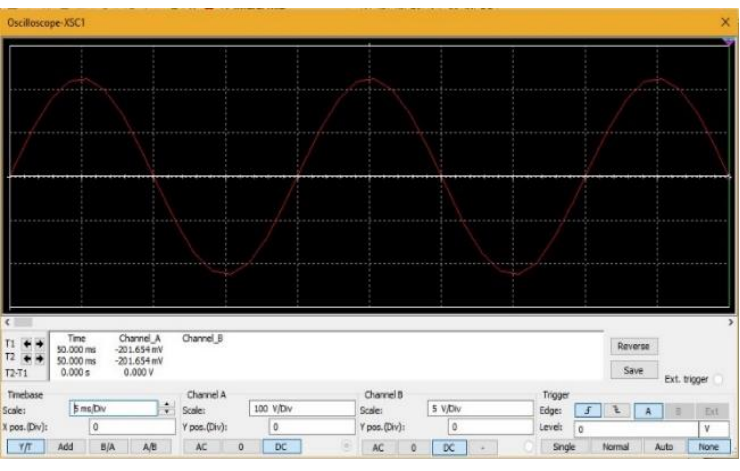

Figure 18. The Experimental output voltage of H-bridge single-phase inverter with the filter

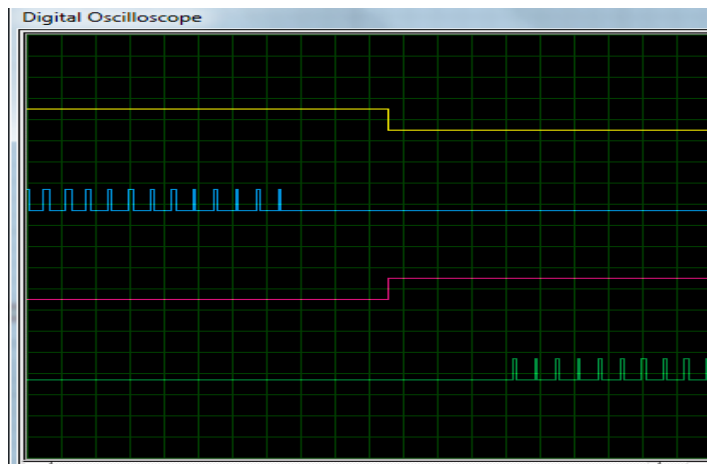

Figure 19. Simulation result of dead time

The experimental hardware set up for the overall system (consists of the proposed two-stage boost converter and a pure sine were wave single-phase inverter with pure a resistive load) is shown in Figure 20. From the analysis and results achieved, the microcontroller has managed to adopt control algorithms in a reasonable real time without further changes in hard ware components and has reduced the complexity of the control circuit of the single phase inverter bridge.Further more, the results attained has improved the output wave form as typical as pure sine wave of the inverter and minimized the dead time control compared by similar researches. The proposed design is simulated in Proteus and PSIM software to assess and evaluate the output results and verified practically.

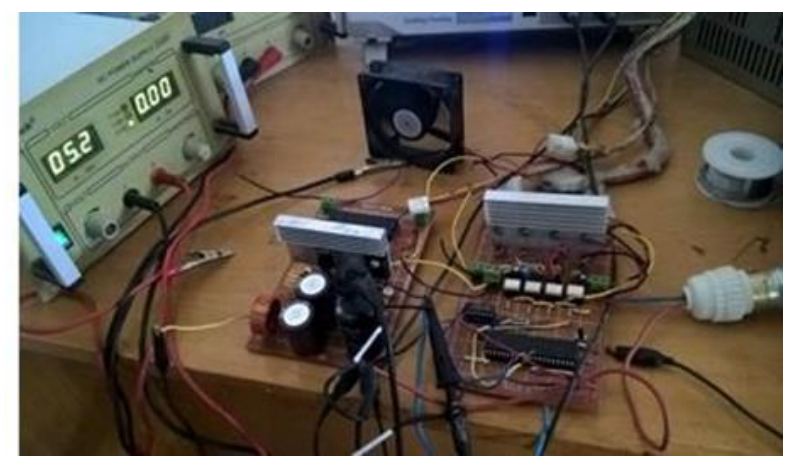

Figure 20. Experimental hardware set up for the overall system

\section{CONCLUSION}

The paper investigated the design and implementation of the two-stage boost converter with high efficiency for single-phase transformerless inverter for PV applications. The converter circuit is planned for the range of input voltage 24-30 V, corresponding output voltage $312 \mathrm{~V}$ and maximum output power of $250 \mathrm{~W}$. Moreover, development and improvement of the control circuit for a single-phase inverter using PIC microcontroller to implement it. The technique of SPWM is used to control the switches of the inverter. The method of SPWM is outstanding to other methods because of making the quality of waveform results better where the THD is $0.84 \%$. The simulation results are accomplished using Proteus and PSIM platform. Also, it's compared with the experimental results performed through the module of the LAB, the output waveform of the inverter is a pure sine wave. Furthermore, dead time is decreased to $63 \mu \mathrm{s}$ versus other conventional results in which dead time reach $180 \mu \mathrm{s}$. Typically, the maximum power tracking of

Development and implementation of two-stage boost converter for single-phase inve ... (Basem E. Elnaghi) 
the proposed solar module is developed by a combination of both two-stage boost converter and PWM inverter, which is not helpful and cooperative in power and energy saving due to the high cost of solar panels, but also it is a developed technique for conducting and controlling AC loads.

\section{REFERENCES}

[1] Y. W. Cho, et al., "Improved single-phase transformerless inverter with high power density and high efficiency for grid-connected photovoltaic systems," IET Renewable Power Generation., vol. 10(2), pp. 166-174, Feb 2016.

[2] T. Freddy, N.A. Rahim, W.P. Hew, et al., "Comparison and analysis of single-phase transformerless grid-connected PV inverters,” IEEE Trans. Power Electron., vol. 29(10), pp. 5358-5369, Oct. 2014.

[3] Y.S. Bae, R.Y. Kim, "Suppression of common-mode voltage using a multicentral photovoltaic inverter topology with synchronized PWM," IEEE Trans. Ind.Electron., vol. 61(9), pp. 4722-4733, Sept. 2014.

[4] M. Amirabadi, A. Balakrishnan, H.A. Toliyat, et al., "High-frequency AC-link PV inverter," IEEE Trans. Ind. Electron., vol. 61(1), pp. 281-291, Jan. 2014.

[5] K K. L. Ashok, et al., "Design and implementation of single-phase inverter without transformer for PV applications," IET Renewable Power Generation, vol. 12(5), pp. 547-554, Mar. 2018.

[6] M. Ouariachi, et al., "Design and realization of a single-phase inverter with numerical control based on an Atmega32," IEEE 14th Int. Multi-Conf. Systems, Signals \& Devices (SSD), Marrakech, Morocco, pp. 239-244, 2017.

[7] A. A. Qazalbash, et al., "Design and implementation of microcontroller based PWM technique for sine wave inverter," IEEE Int. Conf. Power Engineering Energy and Electrical Drives, Lisbon, Portugal, pp. 163-167, 2009.

[8] S. L. Sze and E. H. Yeh, "Improved Single-Phase Split-Source Inverter with Hybrid Quasi-Sinusoidal and Constant PWM," IEEE Trans. Ind. Electron., vol. 64(3), pp. 2024-2031, Mar. 2017.

[9] M. H. Cervantes, et al., "FPGA-based real-time simulation of a full bridge-RL load SPWM inverter," IEEE International Autumn Meeting on Power Electronics and Computing (ROPEC), Mexico City, Mexico, pp. 1-6, 2013.

[10] B. Ismail, S. Taib, et al., "Development of a Single Phase SPWM Microcontroller-Based Inverter," IEEE Int. Power and Energy Conf., Putra Jaya, Malaysia, pp. 437-440. 2006.

[11] S. M. Mohaiminul and M. S. Gazi, "microcontroller based sinusoidal PWM inverter for photovoltaic application," IEEE 1st Int. Conf. development in renewable energy technology, Dhaka, Bangladesh, pp 1-4, 2009.

[12] S. Hannan, S. Aslam and M. Ghayur., "Design and Real-Time Implementation of SPWM based Inverter," International Conference on Engineering and Emerging Technologies (ICEET), Lahore, Pakistan, pp. 1-6, 2018.

[13] J. Soomro, et al., "Design and Analysis of Single-Phase Voltage Source Inverter Using Unipolar and Bipolar Pulse Width Modulation Techniques," Int. Conf. on Advances in Electrical, Electronic and Systems Engineering (ICAEES), Putrajaya, Malaysia, pp. 277-282, 2016.

[14] B. Ismail, et al., "Microcontroller Implementation of single-phase inverter switching strategies," Int. Conf. on Control, Instrumentation and Mechatronics Engineering, Johor, Malaysia, pp. 104-107, 2007.

[15] B. Wu, et al., "A new hybrid boosting converter for renewable energy applications," IEEE Transaction on Power Electronics., vol. 31(2), pp. 1203-1215, Feb. 2016.

[16] B. P. Baddipadiga and M. Ferdowsi, "A High-Voltage-Gain DC-DC Converter Based on Modified Dickson Charge Pump Voltage Multiplier," IEEE Transaction on Power Electronics., vol. 32(10), pp. 7707-7715, Oct. 2017.

[17] R. W. Erickson, and D. Maksimovic, "Steady-State Equivalent Circuit Modeling Losses, and Efficiency," in Fundamentals of power electronics, 2nd ed, New York, USA, springer, pp. 39-56, 2001.

[18] R. Akkaya, and A. A. Kulaksiz, "A microcontroller-based stand- alone photovoltaic power system for residential appliances," ELSEVIER Applied Energy, vol. 78(4), pp. 419-431, Aug. 2004.

[19] S. Daher, et al., "Multilevel Inverter Topologies for Stand Alone PV Systems," IEEE Transaction on Industrial Electronics, vol. 55(7), pp. 2703-2711, Jul. 2008.

[20] S. Daher, et al., "Current demand of high-performance inverters for renewable energy systems, et al.," European Conf. Power Electronics and Applications, Aalborg, Denmark, pp. 1-10, 2007.

[21] A. S. K. Chowdhury, et al., "Design and implementation of a highly efficient pure sine-wave inverter for photovoltaic applications, et al.," IEEE Int. Conf. Informatics, Electronics and Vision (ICIEV), Dhaka, Bangladesh, pp. 1-6, 2013.

[22] M. A. Razzak, et al., "Design of A Grid-Connected Photovoltaic Inverter with Maximum Power Point Tracking Using Perturb and Observe Technique," International Journal of Power Electronics And Drive Systems, vol. 7(4), pp. 1212-1220, Dec. 2016.

[23] P. Chaudhari, et al., "Design of control systems for grid interconnection and power control of a grid tie inverter for microgrid application," IEEE Int. Conf. Signal Processing, Informatics, Communication and Energy Systems (SPICES), Kozhikode, India, pp. 1-5, 2015.

[24] A. F. A. Zaidi, et al., "development of microcontroller-based inverter control circuit for residential wind generator application," Journal of Science and technology, vol. 2(1), pp. 55-77, Jun. 2010.

[25] M. I. Jahmeerbacus and M. Sunassee, "Evaluation of Selective Harmonic Elimination and Sinusoidal PWM for Single-Phase DC to AC Inverters under Dead-Time Distortion," IEEE 23rd International Symposium on Industrial Electronics (ISIE), Istanbul, Turkey, pp. 465-470, 2014.

[26] M. Barukčić, et al., "The irradiance and temperature dependent mathematical model for estimation of photovoltaic panel performances," ELSEVIER Energy Conversion and Management, vol. 101, pp. 229-238, Sep. 2015. 
[27] P. V. Thakre and S. Rangnekar, "Performance analysis of single phase MPPT based photovoltaic inverter topologies and implementation of digital controller TMS320C28027 based PWM signal for single phase bidirectional high frequency link inverter," IET 5th Int. Conf. Advances in Recent Technologies in Communication and Computing, Bangalore, India, pp. 275-287, 2013.

[28] A. Sangari, R. Umamaheswari, "Analysis of Impedance Source Inverter Topologies for Grid integration of PV inverters," International Journal of Power Electronics and Drives, vol. 6(4), pp. 797-807, Dec. 2015.

\section{BIOGRAPHIES OF AUTHORS}

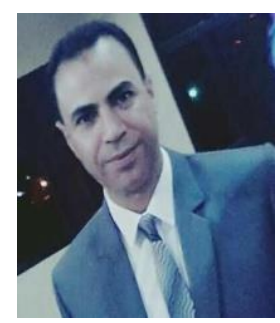

Basem E. Elnaghi received the B.Sc., M.Sc. and Ph.D. degrees in electrical power engineering in 2002 and 2009, and 2015 respectively, from Suez Canal University, Port Said, Egypt. Since 2015, he has been assistant professor with the electrical engineering Department, faculty of engineering, Suez Canal University. His research interests include control of electrical machines and wind energy conversion system.
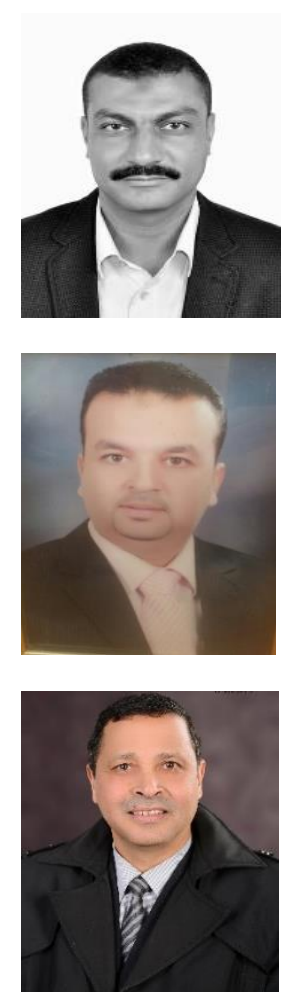

Mohamed. E. Dessouki was born in Bohiera, Egypt in 1976. He received his B.Sc., M.sc. and Ph.D. degrees, from Faculty of Engineering, Suez Canal University in 1999, 2004 and 2010 respectively, all in Electrical Engineering. He joined the Department of Electrical Engineering, Faculty of Engineering, Suez Canal University as a demonstrator in 2000. Then, he became an assistant Lecturer from 2004 to 2010 and has been a Lecturer since 2010. He joined the Department of Electrical Engineering, King Abdulaziz University, Rabigh. His main professional interests include ac and dc drives, direct torque and field-oriented control techniques, and DSP control and power electronics applications.

Dr. M.N. Abdel-Wahab had his B.Sc. from Zagazig University, and then he had his M.Sc and $\mathrm{Ph} . \mathrm{D}$ from Mansoura University. He worked as a super-intended engineer in (Naval Medical Research Unit) NAMRU-3 in Cairo then he participated in upgrading electrical network of Abu_Hamad Air Base as an external electrical officer engineer then he moved to Egyptian Electricity Transmission Company (EETC) as a consultant engineer. Eventually, Dr. M.N. Abdel-Wahab had been appointed as an assistant professor (Teaching Staff Member) in Electrical Engineering Department - Faculty of Engineering - Suez Canal University. He published thirty papers in international journals, national and international conferences.

E. E. EL-Kholy (M'16) was born in Menoufia, Egypt, in 1963. He received the B.Sc., M.Sc., and Ph.D. degrees in electrical engineering from the Faculty of Engineering, Menoufia University, Menoufia, Egypt, in 1986, 1992, and 1996, respectively. He is the Head of the Electrical Engineering Department, Faculty of Engineering, Menoufia University. His main fields of interest include power electronics, ac/dc drives control techniques, active rectifiers, active filters, microgrids, and renewable energy. His interests also extend to real-time control using DSPs and fuzzy applications in power electronics 